January 2016

\title{
Frequency of Retinopathy of Prematurity in a Tertiary Care Hospital
}

Shiyam Sunder Tikmani

Aga Khan University, shiyam.sunder@aku.edu

Tufail Soomro

Ghulam Mohammad Mahar Medial College, Sukkur, Pakistan

Prashant Tikmani

Shaheed Zulfiqar Ali Bhutto Institute of Science and Technology, Karachi, Pakistan

Follow this and additional works at: https://ecommons.aku.edu/pakistan fhs me chs chs

Part of the Congenital, Hereditary, and Neonatal Diseases and Abnormalities Commons, Eye Diseases Commons, Maternal and Child Health Commons, Obstetrics and Gynecology Commons, and the Pediatrics Commons

\section{Recommended Citation}

Tikmani, S. S., Soomro, T., Tikmani, P. (2016). Frequency of Retinopathy of Prematurity in a Tertiary Care Hospital. Journal of Pregnancy and Child Health, 3(5), 1-4.

Available at: https://ecommons.aku.edu/pakistan_fhs_mc_chs_chs/369 


\title{
Frequency of Retinopathy of Prematurity in a Tertiary Care Hospital
}

\author{
Shiyam Sunder Tikmani ${ }^{1}$, Tufail Soomro ${ }^{2^{*}}$ and Prashant Tikmani ${ }^{3}$ \\ ${ }^{1}$ Department of Community Health Sciences, Aga Khan University, Karachi, Pakistan \\ ${ }^{2}$ Department of Pediatrics Ghulam Mohammad Mahar Medial College, Sukkur, Pakistan \\ ${ }^{3}$ Shaheed Zulfiqar Ali Bhutto Institute of Science and Technology, Karachi, Pakistan
}

*Corresponding author: Tufail Soomro, Department of Paediatrics, Ghulam Mohammad Mahar Medical College, Sukkur, Pakistan, Tel: 923337279661; E-mail: drtufailsoomro@hotmail.com

Received date: July 30, 2015; Accepted date: October 21, 2016; Published date: October 25, 2016

Copyright: (C) 2016 Tikmani SS, et al. This is an open-access article distributed under the terms of the Creative Commons Attribution License, which permits unrestricted use, distribution and reproduction in any medium, provided the original author and source are credited.

\begin{abstract}
Introduction: Retinopathy of prematurity (ROP) is one of a preventable cause of blindness in neonates. Screening of preterm infants for ROP in Pakistan is currently under-recognized. The aim of this study was to determine the frequency of retinopathy of prematurity (ROP) in premature and very low birth weight neonates (birth weight $\leq 1500 \mathrm{~g}$ and gestational age $\leq 32$ weeks) in a tertiary care hospital, Karachi, Pakistan.

Methods: This was a cross-sectional study carried out in the neonatal intensive care unit (NICU) of Civil Hospital Sukkur from 1st June 2014 to 17 th June 2015. Preterm neonates with birth weight $\leq 1.5 \mathrm{Kg}$ and gestational age of $\leq$ 32 weeks were referred for ROP eye examination as an outpatient were included in the study after taking consent from parents. Premature neonates with major congenital malformations, chromosomal anomalies or congenital cataract or tumours of the eyes or those who died before eye examinations or did not attend the out-patient department for eye examination were excluded. Eye examination for ROP was performed on all infants, at 4 to 6 weeks chronological age, by a trained ophthalmologist, having at least 10 years of relevant experience.
\end{abstract}

Results: A total of 86 babies enrolled in the study. Of them, $46(53.5 \%)$ were male and 58 (67.4\%) babies were 4 weeks old. ROP was identified in $9(10.5 \%)$ neonates at the first eye examination. ROP was significantly associated with birth weight ( $p$-value 0.031), gestational age ( $p$-value 0.033 ) and chronological age ( $p$-value $<0.001)$.

Conclusion: It was concluded from this study that frequency of ROP was $10.5 \%$. ROP is significantly associated with birth weight, gestational age, and age of the infant.

Keywords: Retinopathy of prematurity; Premature babies; Birth weight; Gestational age; Neonates

\section{Introduction}

Retinopathy of prematurity (ROP) is one of the preventable causes of blindness [1]. It is a disease that affects immature eye vessels of premature infants [2]. Globally, an estimated 1.4 million blind children, of those two third of children live in low- and middle-income countries and $50 \%$ of them are due to ROP $[3,4]$.

Infants with ROP are at higher risk for developing other eye problems in later life5, such as retinal detachment, myopia (nearsightedness), strabismus (crossed eyes), visual field defects, amblyopia (lazy eye), colored vision perception and glaucoma. If identified early, these eye problems can be treated or controlled [5].

The incidence of ROP is much higher in low- and middle-income countries as compared to high-income countries $[1,6]$. The prevalence of ROP in the United States is $0.2 \%, 6.3 \%$ in UK [6,7]. Recent reports from Europe and Australia showed a decreasing trend in incidence of severe ROP $[8,9]$.

Reasons for the high incidence of ROP in low- middle-income countries are 1) high rate of premature births, 2) lack of ROP awareness among family practitioners and parents, lack of skilled personnel or financial constraints, 3) lack of screening and treatment programs in most of the neonatal units $[6,10]$.

Pakistan is low-middle income country with poor health indicators. Unfortunately in Pakistan ROP is currently under-recognized. The incidence of ROP in Pakistan is not known as multi-center large prospective population-based studies had never been conducted. However, some studies from Pakistan reported the frequency of ROP is ranging from $10.5 \%$ [11] to $32.4 \%$ [12].

In the light of above background and given the importance of ROP as a much neglected in our society, we conducted a study in Civil hospital Sukkur which involve the systematic collection and presentation of data to determine the frequency of ROP in premature babies which helps the medical professionals to get aware of the magnitude of the problem and to facilitate in designing appropriate management strategies to prevent ROP.

\section{Methods}

This cross-sectional study was carried out in the neonatal intensive care unit (NICU) of Civil Hospital Sukkur from 1st June 2014 to 17th June 2015. Preterm infants with birth weight $\leq 1.5 \mathrm{Kg}$ and gestational age of $\leq 32$ weeks admitted in NICU between the study period, which was referred for ROP eye examination as an outpatient, were included in the study after taking written informed consent from parents. 
Page 2 of 4

Premature neonates with major congenital malformations, chromosomal anomalies or congenital cataract or tumors of the eyes or those who died before eye examinations or did not attend the outpatient department for eye examination were excluded. Eye examination for ROP was performed on all infants at 4 to 6 weeks chronological age by a trained ophthalmologist, having at least 10 years of experience. Before eye examination, pupils were dilated by instilling topical $0.5 \%$ tropicamide and $0.5 \%$ phenylephrine eye drops 3 times (one minute apart). Indirect ophthalmoscopy was performed using a binocular indirect ophthalmoscope. Lid speculum and scleral depressors were used routinely. The diagnosis of ROP was made based on the amount of abnormal blood vessel development. The stages of ROP are given in Table 1. The information was collected on a predesigned proforma.

\begin{tabular}{|l|l|}
\hline $\begin{array}{l}\text { Stage } \\
\text { ROP }\end{array}$ & of \\
\hline 1 & Thescription is a thin line between the area with blood vessels and the area where blood vessels have not grown yet. \\
\hline 2 & The line between the areas with and without blood vessels widens and thickens into a ridge. \\
\hline 3 & $\begin{array}{l}\text { New blood vessels begin to grow along the ridge and extend into the clear gel that fills the eye, called the vitreous body. These blood vessels can } \\
\text { bleed and form scar tissue. }\end{array}$ \\
\hline $4 \mathrm{~A}$ & The abnormal blood vessels and scar tissue pull on the retina, partially detaching it. In stage 4A, the center of vision called the fovea, is not involved. \\
\hline $4 \mathrm{~B}$ & The retina is still only partially detached, but the fovea is affected usually leaving both the center and peripheral vision impaired to some degree. \\
\hline 5 & The retina is completely detached, severely affecting vision. \\
\hline
\end{tabular}

Table 1: Stages of retinopathy of prematurity.

\section{Statistical analysis}

A non-probability consecutive sampling technique was applied to study sample. Approximately, 200 premature neonates are admitted in Civil hospital Sukkur each year. Assuming a 10.5\%11 prevalence of ROP with an acceptable error of $7 \%$ and a $95 \%$ confidence level, the calculated sample size was 74 subjects. However, we enrolled 80 preterm infants for this study. Data entry and analysis was done through SPSS version 20 (IBM SPSS Statistics, USA)The mean and standard deviation were reported for continuous variables like birth weight and gestational age and frequencies with percentages were presented for categorical variables like gender, mode of delivery, methods of oxygen use and presence or absence of ROP. Chi-square or Fisher exact test was applied to compare categorical variables. P-value of $<0.05$ was considered significant. Stratified analysis was done to assess effect modifiers like gender, birth weight, gestational age, mode of delivery and mechanical ventilation on the outcome. The study was approved by the ethical review committee of the institute.

The study was approved by the ethical review committee of the institute. The primary author got written permission from Pediatric consultant of Civil Hospital Sukkur, who is also a second and corresponding author, to write the first draft.

\section{Results}

A total of 80 babies enrolled in the study. The majority of infants were 4 weeks old accounting for 56 (70\%) cases; 45 (56.3\%) were male and $35(43.8 \%)$ were female with a male to female ratio of 1.15-1. Mean gestational age was $33.43 \pm 1.1$ week; and mean birth weight was $1.43 \pm$ $0.89 \mathrm{~kg}$; among enrolled infants, $61(76.3 \%)$ delivered through spontaneous vaginal delivery and $47(58.8 \%)$ premature infants need mechanical ventilation. ROP was present in $9(10.5 \%$; $95 \% \mathrm{CI}$ : 6.9\%-21.5\%) of babies (Table 2).

\begin{tabular}{|l|l|l|}
\hline & N & $\%$ \\
\hline Chronologic age & & \\
\hline
\end{tabular}

\begin{tabular}{|c|c|c|}
\hline 4 weeks & 56 & 70 \\
\hline 5 weeks & 18 & 22.5 \\
\hline 6 weeks & 6 & 7.5 \\
\hline \multicolumn{3}{|l|}{ Sex } \\
\hline Male & 45 & 56.3 \\
\hline Female & 35 & 43.8 \\
\hline \multicolumn{3}{|l|}{ Gestational age } \\
\hline Mean gestational age & $33.43 \pm 1.1$ & \\
\hline$<30$ weeks & 43 & 53.8 \\
\hline 30-32 weeks & 37 & 46.3 \\
\hline \multicolumn{3}{|l|}{ Birth weight } \\
\hline Mean birth weight & $1.43 \pm 0.89$ & \\
\hline$<1.2 \mathrm{~kg}$ & 42 & 52.5 \\
\hline $1.2-1.5 \mathrm{~kg}$ & 38 & 47.5 \\
\hline \multicolumn{3}{|l|}{ Mode of delivery } \\
\hline Vaginal & 61 & 76.3 \\
\hline C-section & 19 & 23.8 \\
\hline \multicolumn{3}{|l|}{ Mechanical ventilation } \\
\hline Yes & 47 & 58.8 \\
\hline No & 33 & 41.3 \\
\hline \multicolumn{3}{|c|}{ Frequency of retinopathy } \\
\hline Yes & 10 & 12.5 \\
\hline
\end{tabular}


Page 3 of 4

$$
\text { No }
$$$$
70
$$$$
87.5
$$

Table 2: Demographic features of enrolled preterm infants.

There are no significant associations between ROP and sex (p-0.279) and mode of delivery (p-0.183) However, ROP is significantly associated with chronological age of infant $(\mathrm{p}-<0.001)$, gestational age (p-0.014), birth weight $(\mathrm{p}-0.011)$ and infants on mechanical ventilation (p-0.030) (Table 3).



Table 3: Comparison of demographic and clinical features of infants with ROP vs. no ROP.

Stratified analysis showed that infants with gestational age $<30$ weeks, 20.9\% had ROP compared to infants with 30-32 weeks gestational age (p-0.013); infants with birth weight $<1.2 \mathrm{~kg}, 1.2-1.5 \mathrm{had}$ ROP (P-0.010) and infants on mechanical ventilation $19.1 \%$ has ROP compared to infants, not on mechanical ventilation ( $\mathrm{p}-0.027)$.

\section{Discussion}

Advancement in the management of premature babies increased their survival. Hence, increase in the numbers of ROP. In this study, the frequency of ROP was $10.5 \%$. Frequencies reported by other studies were high. In India, the reported [13] incidence of ROP was $27 \%$, in Oman 34\% [14] and in Singapore 29.2\% [15].

The incidence and severity of ROP are highly correlated with the degree of prematurity and birth weight [6,7]. Over $80 \%$ of infants born less than 28 weeks of gestation developed ROP, while only $60 \%$ of infants born 28-31weeks developed ROP [16]. In this study, infants with ROP have a birth weight less than $1.2 \mathrm{Kg}$ and gestational age less than 30 weeks. Studies reported that ROP almost exclusively present in infants with birth weight less than $1500 \mathrm{~g}[17,18]$ and gestational age of fewer than 32 weeks $[19,20]$.

Worldwide, the frequency of blindness due ROP varies significantly from country to country and region to region [6] To estimate the proportion of blindness due to ROP, World Bank plotted blindness data against infant mortality rates (IMR). The plot suggests that countries fall into three categories: countries with IMRs above 60/1000 (Low-income countries) do not have problem of blindness due to lack of neonatal intensive care services or premature babies do not survive long enough to develop severe ROP; countries with very low IMRs, i.e., 9/1000 (high income countries) have lowest rates of ROP because of low rates of prematurity, good neonatal intensive care and monitored supplemental oxygen as well advanced neonatal care services including screening and treatment programs for ROP and countries with IMR ranging from 9-60/1000 live births, middle income countries where ROP emerged as an important cause of blindness $[1,10]$ because of higher rate of teenage pregnancies, premature births, lack of quality intensive neonatal services with variable standards of care and no effective programs for screening and treatment of ROP $[1,10]$.

ROP is becoming a major cause of potentially preventable blindness among children in middle-income countries that have introduced neonatal intensive-care services for preterm and low birth weight babies. The key recommendations are; 1 ) infants with a birth weight of $<1500$ g or gestational age of $<32$ weeks or infants with a birth weight between 1500 and $2000 \mathrm{~g}$ or gestational age of $>32$ weeks with an unstable clinical course, are at high risk of developing ROP and should be screened 2) Parents of babies at risk of developing ROP should be counselled about early detection and treatment of ROP; 3) Follow-up of infants with ROP must be done for disease progression and treatment. Unit-specific criteria with respect to birth weight and gestational age should be established for each NICU with consultation and agreement between neonatologist and ophthalmologist; 4) Neonates with ROP, regardless of whether they require treatment or not, should be examined at regular intervals for associated visual complications such as strabismus, amblyopia, cataract, etc.; 5) retinal examinations in preterm infants should be performed by an expert ophthalmologist; 6) in addition to verbal communication, written information about the screening procedure before the first screening examination should be given to parents and 7) Comfort care should be considered during the screening examination.

\section{References}

1. Kim TI, Sohn J, Pi SY, Yoon YH (2004) Postnatal risk factors of retinopathy of prematurity. Paediatr Perinatal Epidemiol 18: 130-134.

2. American Academy of Pediatrics Section on Ophthalmology (2013) American association of certified orthoptists, screening examination of premature infants for retinopathy of prematurity. Pediatrics 131: 189-195.

3. World Health Organization (2000) Preventing blindness in children. Report of a WHO/IAPB Scientific meeting.

4. Gilbert C (2008) Retinopathy of prematurity: A global perspective of the epidemics, population of babies at risk and implications for control. Early Human Development 84: 77-82.

5. Good WV, Hardy RJ, Dobson V, Palmer EA, Phelps DL, et al. (2005) The incidence and course of retinopathy of prematurity: Findings from the early treatment for retinopathy of prematurity study, Pediatrics 116: 15 .

6. Gilbert C, Fielder A, Gordillo L, Quinn G, Semiglia R, et al. (2005) Characteristics of infants with severe retinopathy of prematurity in 
Citation: Tikmani SS, Soomro T, Tikmani P (2016) Frequency of Retinopathy of Prematurity in a Tertiary Care Hospital. J Preg Child Health 3: 285. doi:10.4172/2376-127X.1000285

Page 4 of 4

countries with low, moderate and high levels of development: Implications for screening programs. Pediatrics 115: e518.

7. Fielder AR, Haines L, Scrivener R, Wilkinson AR, Pollock JI (2002) Retinopathy of prematurity in the UK II: An audit of national guidelines for screening and treatment. Eye 16: 285-291.

8. Arrøe M, Peitersen B (1994) Retinopathy of prematurity: A review of a seven-year period in a Danish neonatal intensive care unit. Acta Pædiatrica 83: 501-505.

9. Keith CG, Doyle LW (1995) Retinopathy of prematurity in extremely low birth weight infants. Pediatrics 95: 42.

10. Gilbert C, Rahi J, Eckstein M, O'Sullivan J, Foster A (1997) Retinopathy of prematurity in middle-income countries. The Lancet 350: 12-14.

11. Sohaila A, Tikmani SS, Khan IA, Atiq H, Akhtar ASM (2014) The frequency of retinopathy of prematurity in premature neonates with a birth weight below $1500 \mathrm{~g}$ and a gestational age less than 32 weeks: A study from a tertiary care hospital in a lower-middle income country. PLoS ONE 9: e100785.

12. Taqui AM, Chaudhry TA, Ahmad K, Salat MS (2008) Retinopathy of prematurity: Frequency and risk factors in a tertiary care hospital in Karachi, Pakistan. J Pak Med Assoc 58: 186-190.

13. Maheshwari R, Kumar H, Paul VK, Singh M, Deorari AK, et al. (1996) Incidence and risk factors of retinopathy of prematurity in a tertiary care new-born unit in New Delhi. Natl Med J India 9: 211-214.
14. Bassiouny MR (1996) Risk factors associated with retinopathy of prematurity: A study from Oman. Journal of Tropical Pediatrics 42: 355.

15. Shah VA, Yeo CL, Ling YL, Ho LY. (2005) Incidence, risk factors of retinopathy of prematurity among very low birth weight infants in Singapore. Ann Acad Med Singapore 34: 169-178.

16. Good WV (2004) Early treatment for retinopathy of prematurity cooperative group. Final results of the early treatment for retinopathy of prematurity (ETROP) randomized trial. Trans Am Ophthalmol Soc 102: 233-248.

17. Allegaert K, Verdonck N, Naulaers G, Cossey V, Devlieger H, et al. (2003) Incidence, perinatal risk factors, visual outcome and management of threshold retinopathy. Bull Soc Belge Ophtalmol 287: 37-42.

18. Schulenburg WE, Tsanaktsidis G (2004) Variations in the morphology of retinopathy of prematurity in extremely low birth weight infants. British Journal of Ophthalmology 88: 1500.

19. Palmer EA, Hardy RJ, Dobson V, Phelps DL, Quinn GE, et al. (2005) Cryotherapy for retinopathy of prematurity cooperative group. 15 year outcomes following threshold retinopathy of prematurity: Final results from the multicenter trial of cryotherapy for retinopathy of prematurity. Arch Ophthalmol 123: 311-318.

20. Palmer EA, Phelps D (1986) Multicenter trial of cryotherapy for retinopathy of prematurity. Pediatrics 77: 428. 